\title{
Cerebrovascular Dysfunction Following Subfailure Axial Stretch
}

\author{
E. David Bell, ${ }^{a, b}$ Anthony J. Donato, ${ }^{c}$ Kenneth L. Monson ${ }^{a, b^{*}}$ \\ ${ }^{a}$ Department of Bioengineering, University of Utah, Salt Lake City, UT, USA \\ ${ }^{b}$ Laboratory of Head Injury and Vessel Biomechanics, Department of Mechanical Engineering, University of Utah, \\ Salt Lake City, UT, USA \\ ${ }^{c}$ Department of Internal Medicine, Division of Geriatrics, University of Utah, Salt Lake City, UT, USA \\ *Corresponding Author: 1495 E. 100 S., MEK 1550, Salt Lake City, UT 84112; ken.monson@utah.edu
}

\begin{abstract}
$\underline{\text { Abstract }}$
Cerebral blood vessels are vital to maintaining the health of the brain. Traumatic brain injury (TBI) commonly results in autoregulatory dysfunction and associated failure of cerebral vessels to maintain homeostasis in the brain. While post-injury changes to brain biochemistry are known to contribute to this dysfunction, tissue deformation may also directly alter vascular smooth muscle cell (SMC) function. As a first step toward understanding stretch-induced dysfunction, this study investigates the effect of overstretch on the contractile behavior of SMCs in middle cerebral arteries (MCAs). We hypothesized that vessel function is altered above a threshold of stretch and strain rate.
\end{abstract}

Twenty-four MCAs from Sprague Dawley rats were tested. Following development of basal SMC tone, vessels were subjected to increasing levels of isosmotic extracellular potassium $\left(\mathrm{K}^{+}\right)$. Samples were then subjected to an axial overstretch of either $1.2 * \lambda_{\mathrm{IV}}$ or $1.3 * \lambda_{\mathrm{IV}}$ at strain rates of $0.2 \mathrm{~s}^{-1}$ or $20 \mathrm{~s}^{-1}$. Following overstretch, SMC contractile behavior was measured again, both immediately and 60 minutes after overstretch. Control vessels were subjected to the same protocol but without overstretch. SMC contractile behavior was characterized using both percent contraction $(\% \mathrm{C})$ relative to the fully dilated inner diameter and the $\mathrm{K}^{+}$dose required to evoke 
the half maximal contractile response (EC50). Control vessels exhibited increased sensitivity to $\mathrm{K}^{+}$in successive characterization tests, so all effects were quantified relative to the time-matched control response.

Samples exhibited the typical biphasic response to extracellular $\mathrm{K}^{+}$, dilating and contracting in response to small and large $\mathrm{K}^{+}$concentrations, respectively. As hypothesized, axial overstretch altered SMC contractile behavior, as seen in a decrease in \%C for sub-maximal contractile $\mathrm{K}^{+}$doses $(\mathrm{p}<0.05)$ and an increase in EC50 $(\mathrm{p}<0.01)$, but only for the test group stretched rapidly to $1.3 * \lambda_{\mathrm{IV}}$. While the change in $\% \mathrm{C}$ was only significantly different immediately after overstretch, the change to EC50 persisted for 60 minutes. These results indicate that deformation can alter SMC contractile behavior and thus potentially play a role in cerebrovascular autoregulatory dysfunction independent of the pathological chemical environment in the brain post-TBI.

Keywords: traumatic brain injury; rat cerebral blood vessels; autoregulatory dysfunction; damage

\section{$\underline{1 \text { Introduction }}$}

Traumatic brain injury (TBI) is a devastating cause of disability, leading to an estimated 53,000 deaths annually in the United States alone (Coronado et al., 2011), with the incidence of TBI increasing significantly across the globe (Maas et al., 2008). While this death toll is staggering, the majority of the estimated 2.4 million annual cases in the United States (CDC, 2013) result in survival, highlighting the importance of clinical methods to reduce the risk of secondary complications. 
The cerebrovasculature plays a critical role in the maintenance of the healthy brain. Specifically, the ability of the cerebral vessels to generate intrinsic tone in the smooth muscle cells (SMCs) (Ursino, 1994), and then to alter that level of tone to maintain appropriate cerebral blood flow (CBF), is vital to the maintenance of homeostasis in the brain (Lassen, 1974;Ursino, 1994). This process, known as autoregulation, is often disrupted following TBI (Martin et al., 1992;Golding et al., 1999a;Zubkov et al., 2000;Golding, 2002;Kenney et al., 2016), resulting in unfavorable clinical outcomes (Robertson et al., 1992;Czosnyka et al., 1996). Autoregulation is accomplished through multiple mechanisms (Johnson, 1986;Udomphorn et al., 2008).

Endothelial cells (ECs) can release compounds to produce both vasodilation and vasoconstriction (Armstead, 1999;Hamel, 2006;Seals et al., 2011). Smooth muscle cell function can also be directly affected by mechanical signals (Bayliss, 1902;Davis, 1993;Osol et al., 2002), a process known as myogenic contraction, as well as by non-endothelial chemicals (Kontos et al., 1977; Talman and Nitschke Dragon, 2007). For example, potassium $\left(\mathrm{K}^{+}\right)$in surrounding tissue interacts directly with SMCs to produce either dilation or contraction.

Previous experiments have demonstrated vascular dysfunction following TBI. In vivo studies have shown that both EC-mediated dilation (Ellison et al., 1989;Kontos and Wei, 1992;Toklu et al., 2015) and myogenic pressure response (Golding et al., 1998a; Mathew et al., 1999) are impaired after TBI. However, some in vitro studies have shown no change in function in vessels removed quickly from the brain post-TBI (Bukoski et al., 1997;Golding et al., 1999b). This has led some to conclude that dysfunction following TBI is not due to mechanical damage to the vessels but is instead associated with the milieu of the injured brain. However, it should be noted that vessels tested in vitro following TBI were taken from a portion of the brain either far removed from the site of injury (Bukoski et al., 1997) or where the mechanical deformation 
experienced by the tested samples was not well defined (Golding et al., 1999b). Therefore, these studies do not directly address mechanical damage as a potential contributor to autoregulatory dysfunction.

Mechanical injury of the cerebrovasculature might be expected to alter both passive mechanical properties and cellular function through damage to the extracellular matrix and cells, respectively. Our group has previously shown that the passive mechanical properties of cerebral vessels are altered following in vitro axial stretch beyond the in vivo length (Bell et al., 2015). Others have shown that the degree of TBI-induced autoregulatory dysfunction in rats, along with the time frame for the onset of that dysfunction, are dependent on impact velocity in closed head injury (Prat et al., 1997). This suggests a role for mechanics in cellular dysfunction but may also simply indicate that more dysfunction results from a more severe injury.

The objective of the current study was to begin to define the role of mechanics in cerebrovascular dysfunction by evaluating the contractile behavior of isolated rat middle cerebral arteries (MCAs) before and after axial overstretch. We hypothesized that subfailure mechanical deformation would induce a change in the contractile behavior of rat MCAs that would be dependent upon both the level and rate of applied overstretch. While many pathways of dysfunction could be explored, we chose to evaluate SMC function directly by measuring vessel response to increasing levels of isotonic (Golding et al., 2000) extracellular potassium $\left(\mathrm{K}^{+}\right)$, a pathway independent of the endothelium.

\section{$\underline{2 \text { Methods }}$}

\subsection{Sample acquisition and preparation}


The right MCA was dissected from 24 male Sprague Dawley rats (371 \pm 24 grams). All procedures met the requirements established by the Institutional Animal Use and Care Committee at the University of Utah. Rats were euthanized through isoflurane overdose and decapitation. The brain was immediately removed and placed in $5^{\circ} \mathrm{C}$ physiological saline solution (PSS) for dissection of the MCA (Donato et al., 2007). Side branches were ligated with individual fibrils from unwound 6-0 silk suture. The MCA was cannulated with glass needles approximately $200 \mu \mathrm{m}$ in diameter and secured with 11-0 monofilament nylon suture. Ceramic coated forceps (Roboz Surgical Instruments, Gaithersburg, MD) were utilized for dissection and mounting in order to prevent any depolarization of SMCs via environmental static electricity.

\subsection{Test Apparatus}

The cannulated MCA was mounted horizontally in a temperature controlled $\left(37^{\circ} \mathrm{C}\right) \mathrm{PSS}$ bath. The bath included a glass window in its base for light and a submersible glass viewing window above the MCA. One needle was stationary during testing but was mounted to an X-Y stage (MS-125-XY, Newport, Irvine, CA) that allowed fine adjustment for needle alignment. The other needle was mounted to the tester via a horizontal, low friction sled that was connected to a voice coil actuator (MGV52-25-1.0, Akribis, Singapore). The actuator moved the proximal needle horizontally along the sled track, axially stretching the MCA. Actuator position was given by a digital encoder (resolution $1.0 \mu \mathrm{m}$ ). A digital video camera (PL-A641, Pixelink, Ottawa, Canada) mounted to a light microscope (Ziess 2000C, Carl Zeiss Microscopy, Thornwood, NY) recorded vessel deformations during testing. The MCA was perfused with warm PSS originating from a hanging, open syringe to provide fluid pressure. The fluid path passed through the proximal needle, mounted MCA, and the distal needle, to a closed valve that prevented flow. Inline pressure transducers (26PCDFM6G, Honeywell, Golden Valley, MN) were located both 
proximal and distal to the mounted MCA, equidistant from the vessel. The average between these two transducers was taken to be the pressure inside the MCA, or the luminal pressure. A custom LabVIEW program (National Instruments, Austin, TX) provided test control and data and video acquisition. Vessel diameter was estimated using an edge detection tool that utilizes a histogram of pixel intensity along a line perpendicular to the long axis of the mounted vessel. Each estimated diameter was derived from the average of multiple lines (Vision Assistant, National Instruments).

\subsection{Test Procedure}

After mounting the MCA, luminal pressure was slowly raised from $2 \mathrm{kPa}$ to the testing pressure of $6.65 \mathrm{kPa}(50 \mathrm{mmHg})$ in approximately $0.5 \mathrm{kPa}$ increments every 5 minutes. During this period, the length of the vessel was also gradually increased to the approximate in vivo length $\left(\lambda_{\mathrm{IV}}\right)$, corresponding to an axial stretch of $\lambda_{\mathrm{z}}=1.1$ (Bell et al., 2013). Once the MCA reached test pressure, it was allowed to equilibrate for 40 minutes in order to develop basal smooth muscle tone. Vessels that failed to develop basal tone or that leaked were discarded. Throughout the entire duration of MCA testing, the PSS in the bath was changed at least every 20 minutes.

The MCA was then subjected to a $\mathrm{K}^{+}$dose response test to characterize the sample specific baseline response. Serially increasing doses of $\mathrm{K}^{+}$were applied externally by changing the PSS in the bath for PSS with altered $\mathrm{K}^{+}$concentrations but equivalent osmolarity. After 5 minutes of exposure to each $\mathrm{K}^{+}$concentration $(10,30,40,60$, and $100 \mathrm{mM})$, the inner diameter was measured from images. Following a complete $\mathrm{K}^{+}$dose response test, the bath was rinsed and the MCA was allowed to equilibrate for 30 minutes to allow basal tone to redevelop. 
Following the re-equilibration period, the MCA was stretched beyond its in vivo length to one of two stretch levels $\left(\lambda_{\mathrm{z}}=1.2 * \lambda_{\mathrm{IV}}\right.$ or $\left.1.3 * \lambda_{\mathrm{IV}}\right)$ at one of two strain rates $\left(0.2\right.$ or $\left.20 \mathrm{~s}^{-1}\right)$, giving 4 overstretched sample groups ( $\mathrm{n}=4$ or 5 each). The $\mathrm{K}^{+}$dose response test was then repeated twice more with a 30 minute equilibration period in between, providing a characterization of SMC contractility initiated both immediately and 60 minutes after overstretch. After the final dose response test, the bath PSS was replaced by an isosmotic calcium free PSS (Donato et al., 2007), and the MCA was allowed to dilate for 30 minutes to obtain a maximum diameter measurement. Finally, to ensure complete dilation, sodium nitroprusside (SNP: $10^{-4} \mathrm{mM}$ ) was added to the bath. The fully dilated inner diameter was measured from images once the diameter was stable, approximately 3 minutes after SNP exposure. To ensure that any changes following overstretch were not simply due to MCA degradation, time matched control tests were performed without overstretch $(n=5)$.

\subsection{Data analysis}

The results of $\mathrm{K}^{+}$dose response tests were quantified using percent contraction (\%C), calculated as (Eq. 1):

$$
\% C=\frac{\left(D_{M}-D_{C}\right)}{D_{M}} * 100
$$

where $D_{M}$ is the maximum dilated inner diameter and $D_{C}$ is the current measured inner diameter. With this definition, percent contraction, $\% \mathrm{C}$, is $100 \%$ for a closed lumen and $0 \%$ for a fully dilated lumen. Because the observed baseline level of contraction varied dramatically from sample to sample, we also compared the post-overstretch contraction of each specimen to its baseline value at the same $\mathrm{K}^{+}$dosage by calculating $\Delta \% \mathrm{C}$ (Eq. 2 ). 


$$
\Delta \% C=(\text { Post-overstretch } \% C)-(\text { Pre-overstretch } \% \text { C })
$$

Additionally, the $\mathrm{K}^{+}$dosage resulting in half maximum contraction (EC50) was also calculated by fitting the normalized dose response data (excluding baseline values) to a fourparameter logistic function (Eq. 3) (Finney, 1976;Jiang and Kopp-Schneider, 2014).

$$
y=\min +\frac{(\max -\min )}{\left(1+\operatorname{abs}\left(\frac{x}{\log _{10}(E C 50)}\right)^{\text {Hillslope }}\right)}
$$

The parameters $\min$ and $\max$ are the minimum and maximum level of contraction, while $x$ and $y$ are $\log _{10}$ applied $\mathrm{K}^{+}$concentration and resulting normalized $\% \mathrm{C}$, respectively. Hillslope is the slope of the central portion of the curve. Units for EC50 are mM. To normalize between testing groups, all \%C data gathered were adjusted such that $0 \%$ still corresponded to the fully dilated diameter and $100 \%$ corresponded to the median maximally observed contraction over all tests performed in that group (pre- or post-overstretch). Further, for fitting of dose response data to Eq. 3, the parameters min, max, and Hillslope were held constant over all three dose response tests performed on that test group. The appropriateness of this constraint on the fitting parameters was confirmed with an F-test for parallelism between curves, as recommended by SigmaPlot (San Jose, CA), which showed the reduction did not statistically affect the resulting EC50 values. Finally, the percent change of EC50 (\% $\%$ EC50) for post-overstretch dose response tests was calculated relative to the vessel specific pre-overstretch EC50 value (Eq. 4), 


$$
\% \Delta E C 50=100 *\left(\frac{E C 50_{\text {Post }}-E C 50_{\text {Pre }}}{E C 50_{\text {Pre }}}\right)
$$

where EC50 Pre and EC50 Post are the EC50 values for a sample in pre-overstretch and postoverstretch tests, respectively.

Statistical analysis was performed to evaluate the significance of the overstretch parameters. For comparison of $\Delta \% \mathrm{C}$, a Levene test was first used to determine if the variances were statistically different. When variances were not different, a one way ANOVA, followed by a Tukey-Kramer post-hoc test, was performed. For comparisons with statistically different variances, Welsh's ANOVA, followed by Games-Howell post-hoc tests, were performed to determine significance. The significance threshold used for the Levene tests, as well as for the various ANOVAs and post-hoc tests, was $\mathrm{p}<0.05$. Both the EC50 values within a test group over time, as well as the $\% \triangle \mathrm{EC} 50$ between groups, were compared using one way ANOVA tests followed by post-hoc two way t-tests utilizing a Bonferroni correction factor, with $\mathrm{p}<0.05$ indicating significance. The EC50 and \% $\%$ EC50 post-hoc tests required a resulting corrected pvalue below 0.01 for significance. A preliminary analysis utilizing a multivariate generalized linear model (MiniTab, State College, PA) showed that time after overstretch did not play a significant role in the metrics used, so time was excluded as an independent variable, and only comparisons to the time matched control values were utilized for statistical analysis.

\section{$\underline{3 \text { Results }}$}

Twenty four arteries were successfully tested. Mean ( \pm standard deviation) in vivo length and fully dilated inner diameter of these specimens were $0.61( \pm 0.13)$ and $0.25( \pm 0.02) \mathrm{mm}$, 
respectively. The overstretch parameters and number of samples for each of the test groups are detailed in Table 1.

As increasing doses of $\mathrm{K}^{+}$were applied, the level of observed contraction followed the previously observed biphasic potassium response for rat cerebral vessels (Figure 1) (Johnson et al., 1998;Golding et al., 2000), dilating with exposure to the lower concentration (10 mM KCl) and exhibiting increasing levels of contraction with higher doses $(30-100 \mathrm{mM} \mathrm{KCl})$. In the control group, the observed levels of $\% \mathrm{C}$ at a given $\mathrm{K}^{+}$dosage increased with successive dose response tests for all but the dilatory dose $(10 \mathrm{mM})$ and the maximal dose $(100 \mathrm{mM})$ (Figure 2 (A)). This change in sub-maximal $\% \mathrm{C}$ for subsequent $\mathrm{K}^{+}$tests was attributed to sensitization of the SMCs to potassium-evoked contraction.

Following overstretch, vessel contraction followed similar overall patterns as controls, except that higher and faster overstretch tended to decrease the ability of a vessel to contract (Figure 2). However, these changes were only statistically significant $(\mathrm{p}<0.05)$ for the vessels rapidly stretched to $1.3 * \lambda_{\mathrm{IV}}$ and only for sub-maximal contractile doses $(30-60 \mathrm{mM} \mathrm{KCl})$ immediately following overstretch. Contractions at 60 minutes post-overstretch displayed similar patterns but were not statistically significant, likely due to relatively high variability in the control group at 60 minutes. This was also true of maximal dose contractions both immediately and 60 minutes after overstretch.

The four-parameter logistic function (Eq. 3) was successful at calculating EC50 for the various test groups, but the deviations within the groups were large (Table 2). As was observed for $\Delta \% \mathrm{C}$ results in controls, EC50 values decreased with repeated dose response tests for the control group, though the reductions were not statistically significant $(\mathrm{p}=0.67)$. Similarly, pre- 
and post-overstretch EC50 values were not statistically different for any of the overstretch groups, likely due to the observed large standard deviations.

In order to overcome these sample specific variations, $\% \Delta \mathrm{EC} 50$ values were calculated. The only overstretch group that showed a statistical difference relative to the time-matched controls was the $1.3 * \lambda_{\text {IV }}$ fast group $(\mathrm{p}<0.01)$ (Figure 3), which agrees well with findings associated with $\Delta \% \mathrm{C}$. However, in contrast to the $\Delta \% \mathrm{C}$ statistical analysis, the $\% \Delta \mathrm{EC} 50$ values were statistically different both immediately $(\mathrm{p}=0.0046)$ and 60 minutes $(\mathrm{p}=0.0072)$ postoverstretch, further evidence that the lack of statistical significance in $\Delta \% \mathrm{C} 60$ minutes postoverstretch in this group is due to the variability in the time-matched control $\Delta \% \mathrm{C}$ data.

\section{$\underline{4 \text { Discussion }}$}

The goal of this study was to determine if potassium-evoked contractile behavior of cerebral SMCs is altered following axial mechanical stretch. Results show that axial overstretch at the levels tested did not affect the baseline or maximum contraction levels. However, there was a reduction in contractility at sub-maximal contraction levels, shown by a decrease in $\Delta \% \mathrm{C}$

and mirrored by an increase in EC50, but statistically significant changes were found only for the largest axial stretch and strain rate investigated. There was no recovery of the EC50 values over the 60 minutes following overstretch. This research supports the theory that TBI-induced autoregulatory dysfunction may be caused directly by mechanical insult, as well as by the altered chemical milieu in the brain (DeWitt and Prough, 2003).

While both high stretch $\left(1.3^{*} \lambda_{\mathrm{IV}}\right)$ and high loading rate $\left(20 \mathrm{~s}^{-1}\right)$ were required to produce statistically significant alterations in vessel response, there were clear trends between overstretches of 1.2 and 1.3 at both the low and high loading rates, indicating an important role 
of stretch magnitude. To put the overstretch values in context, the low and high stretch magnitudes used in this study coincide with approximately $65 \%$ and $85 \%$, respectively, of the in vivo stretch at failure for these vessels (Bell et al., 2013). As a result, the overstretch values used should be considered relatively severe. Results also indicate a dependence on loading rate. Brain tissue strain rates during head impact vary widely depending upon loading conditions, with a recent study reporting values for deep brain tissue, where deformations were not large, between approximately 10 and $100 \mathrm{~s}^{-1}$ (Hardy et al., 2007). Our highest rate of $20 \mathrm{~s}^{-1}$ should thus be considered mild, with the expectation that impairment would be more pronounced at higher rates.

The $\mathrm{K}^{+}$concentrations at which overstretch altered SMC response provide insight into possible mechanism for the observed changes. All test groups had unchanged levels of $\Delta \% \mathrm{C}$ for the baseline as well as the $10 \mathrm{mM} \mathrm{K}$ dilational response. At these lower concentrations of $\mathrm{K}^{+}$, it has been shown that the inward rectifying potassium $\left(\mathrm{K}_{\mathrm{ir}}\right)$ channels (responsible for dilation) dominate the SMC response (Johnson et al., 1998;Golding et al., 2000). There are no studies todate linking $\mathrm{K}_{\text {ir }}$ channel dysfunction with the mechanical insult associated with TBI, and the present study appears to confirm the lack of a connection between these. While $\mathrm{K}_{\text {ir }}$ channel impairment has been observed following ischemia reperfusion injury (Marrelli et al., 1998; Bastide et al., 1999), it has been suggested that this observed impairment may be due to lower density of these channels rather than reduced channel function (Bastide et al., 1999).

It was also observed that the $\Delta \% \mathrm{C}$ at the maximum $\mathrm{K}^{+}$dosage was unaffected by overstretch, but sub-maximal levels of contraction were decreased in the test group with the highest and fastest overstretch. When depolarization of the SMC membrane occurs, both voltage sensitive calcium channels (VSCCs) and $\mathrm{K}_{\text {ir }}$ channels are activated, evoking contraction and 
dilation, respectively. As noted above, the $\mathrm{K}_{\mathrm{ir}}$ channels dominate at mild levels of depolarization and the net result is dilation. At higher levels of depolarization (such as with $\mathrm{K}^{+}$doses above 10 $\mathrm{mM})$, the net result is contraction. VSCCs have an opening probability that is a continuous function of membrane potential, rather than having a set membrane potential opening threshold (Smirnov and Aaronson, 1992). As a result, their influence grows with potassium concentration, overwhelming the $\mathrm{K}_{\mathrm{ir}}$ channels to produce contraction at the sub-maximal levels studied. At the highest potassium dosage, both VSCC behavior and the structural integrity of the contractile mechanisms in the SMCs are expected to dictate the maximal level of contraction. In the absence of other potential contractile mechanisms, our observation that sub-maximal contractile behavior was affected by overstretch, while the maximal $\Delta \% \mathrm{C}$ was not, suggests that axial overstretch alters the opening probability function for the VSCCs without necessarily damaging the underlying contractile structures, such as the myosin-actin complexes.

Overstretch of cerebral arteries has also been shown previously to result in an increase in mechanical compliance, also known as softening (Bell et al., 2015). While that previous study only investigated the effect of axial overstretch on the axial passive mechanical properties, the helical nature of collagen fibers in MCAs suggests that axially-induced microstructural damage would also affect the circumferential direction. The concept of axial overstretch affecting circumferential behavior is further supported by the observed decrease in sub-maximal contractile response in the current study. As noted above, this could be attributed to altered contractile behavior in helically oriented SMCs, but axial softening occurred with even small amounts of stretch beyond the in vivo level in the previous study. Although those experiments were conducted on sheep MCAs, it is almost certain that there were some overstretch-induced changes in the extracellular matrix of vessels in the present study, though it is not yet known how 
those changes might have influenced vessel contractility. As a result, the precise mechanisms responsible for the functional impairment observed in the present study remain undefined.

A limited number of previous studies have similarly investigated the response of blood vessels to controlled mechanical stretch. Vasospasm lasting up to 20 minutes was produced by manipulating subarachnoid connective tissue attached to cerebral arteries in vivo, but not when the vessels themselves were deformed (Arutiunov et al., 1974). Dynamic mechanical stretch applied directly to isolated femoral arteries has also led to vasospasm, but this was shorter in duration, lasting 2 minutes or less (Boock, 1991). Longer term effects, lasting at least 24 hours, have been observed in cultured SMCs exposed to rapid mechanical stretch (Alford et al., 2011). Another investigation explored $\mathrm{K}^{+}$dose response, as in our study, of rat basilar arteries following in vivo blast exposure but found no change in \%C or EC50 values (Toklu et al., 2015). The lack of any change in contraction could be related to methodological differences between studies but could also be due to differences in mode, magnitude, and rate of loading. Regardless, each of these cited studies seems to be in conflict with the present findings where smooth muscle activity was reduced following overstretch. However, another group similarly demonstrated impairment of contractility in response to $\mathrm{KCl}$ for up to 7 days following hyperdistension of rat carotid artery in vivo, though the primary loading mode in that case was circumferential (Jamal et al., 1992). Reasons for differences between the present and previous studies are not known, but variations in loading conditions and vessel type may be important factors.

The present findings show that rapid deformation alters cerebral artery function in isolation, but it is not currently clear how these results might relate to TBI-induced vascular dysfunction. It is known that global CBF is commonly reduced following TBI (DeWitt and Prough, 2003). In cases with focal injury, as in controlled cortical impact, CBF has been shown 
to be particularly reduced in the region of tissue damage (Golding et al., 1998a), suggesting that deformation at the time of injury plays an important role in subsequent CBF reductions. In the present study, however, the observed decrease in \% $\mathrm{C}$ at sub-maximal levels appears to be inconsistent with a reduction in $\mathrm{CBF}$. It is important to recognize that our investigation examined SMC contraction following rapid overstretch in the absence of the many other chemical and physical factors that would also be contributing to vessel behavior post-TBI. As a result, it is not surprising that results appear to be inconsistent with clinical observations of the injured brain as a whole. Findings here provide insight into one small piece of a larger puzzle that will hopefully be helpful in future CBF modeling efforts. Additionally, the high stretch value used in the study is near that required for structural failure of a vessel. If tissue throughout the brain experienced this level of deformation, it would be devastated and there would be little concern for vascular dysfunction. However, focal loading commonly produces deformations that exceed, or nearly exceed, structural limits of both brain and vessel tissue within relatively small regions. Findings from the present study are thus most relevant to such a situation where better understanding of vessel behavior may lead to therapies that limit the growth of a lesion.

We chose to investigate the effect of mechanical overstretch on SMC function using isosmotic elevated extracellular $\mathrm{K}^{+}$concentrations. Following TBI, there is frequently an increase in extracellular $\mathrm{K}^{+}$in the brain released by neurons, as high as 50-60 mM (Takahashi et al., 1981;Katayama et al., 1990;Nilsson et al., 1993;Golding et al., 2000), that typically returns to normal within an hour (Nilsson et al., 1993). This TBI-related increase in extracellular $\mathrm{K}^{+}$is hyperosmotic. It has been shown previously that the observed dilation and contraction evoked by hyperosmotic $\mathrm{K}^{+}$increases are endothelium dependent, whereas isosmotic $\mathrm{K}^{+}$increases lead to endothelium independent dilation and contraction (Golding et al., 2000). Therefore, isosmotic $\mathrm{K}^{+}$ 
doses were used in the present study, rather than the clinically observed hyperosmotic $\mathrm{K}^{+}$ increase, in order to prevent any potential mechanically induced endothelial damage from corrupting the evaluation of SMC function. However, the endothelium was intact and could have added to some of the SMC behavior observed, but any such contributions would be expected to be small compared to the direct effect of $\mathrm{K}^{+}$.

It should be noted that while the MCA was used here to determine the effect of mechanical overstretch on SMC function, pial arteries would typically experience larger deformations than the MCA during a head impact due to the interaction of the brain with the interior of the skull, but we expect that the behaviors of the MCA and nearby pial vessels are similar. Together, these vessels provide a large proportion of the overall resistance in the cerebral circulation (Harper et al., 1984;Faraci and Heistad, 1990) and thus protect the microvasculature from elevated pressures. Use of the MCA in the present study is also helpful for comparison with other animal models of TBI autoregulatory dysfunction where the MCA is commonly characterized (Bukoski et al., 1997;Golding et al., 1998a;Golding et al., 1998b;Mathew et al., 1999; Golding et al., 2000;Bell et al., 2013).

The internal pressure for the mounted samples was $6.65 \mathrm{kPa}(50 \mathrm{mmHg})$. While this pressure is below the mean arterial pressure of $80 \mathrm{mmHg}$ previously measured in rats (Barry et al., 1982), it is within the pressure range of autoregulation for these vessels (Golding et al., 1998b). Further, since the myogenic response of vascular smooth muscle results in greater baseline contraction at higher pressures (Bayliss, 1902;Golding et al., 1998b), the lower pressure of $50 \mathrm{mmHg}$ allows for a larger range of observable contraction upon application of elevated extracellular $\mathrm{K}^{+}$. This lower pressure is also similar to that used in previous TBI studies (Golding et al., 1999b; Toklu et al., 2015). Additionally, preliminary tests in the present study confirmed 
that a higher pressure of $10.5 \mathrm{kPa}(80 \mathrm{mmHg})$ produced higher levels of basal \% $\mathrm{C}$ without changing the maximal level of \%C. Therefore, the higher pressure did not allow as wide of a range on $\% \mathrm{C}$ over which to observe stretch related changes. As this smaller range would make subtle changes in post-overstretch contraction more difficult to detect, the lower pressure level (6.65 $\mathrm{kPa}$ or $50 \mathrm{mmHg}$ ) was selected for testing.

In summary, the reported experiments show that axial overstretch changes the contractile behavior of primarily circumferentially oriented vascular SMCs, independent of the altered chemical environment in the injured brain. While the observed differences are small, when combined with the mechanical softening that follows overstretch (Bell et al., 2015), these changes could contribute to the ongoing TBI disease state. However, the influence of deformation on myogenic and endothelium-mediated mechanisms of smooth muscle function remains to be studied. A better understanding of vessel injury may lend insight into why some traumatic lesions progress (Narayan et al., 2008;Simard et al., 2009) and whether some persistent conditions, such as mild TBI (Len and Neary, 2011) and second impact syndrome (Cantu and Gean, 2010;Laskowski et al., 2015), may be partially mediated by ongoing cerebrovascular dysfunction. Such understanding may also play a role in potential treatments for autoregulatory dysfunction.

\section{$\underline{5 \text { Conflict of Interest Statement }}$}

E. David Bell is an employee of Bard Access Systems, Inc. ("Bard"). Bard was not involved in this study in any respect, and the findings of the study are the sole opinion of the authors. 


\section{$\underline{6 \text { Acknowledgements }}$}

This work was supported in part by the National Institutes of Health (5K25HD048643) and the Department of Defense (W81XWH-08-1-0295).

\section{References}

Alford, P.W., Dabiri, B.E., Goss, J.A., Hemphill, M.A., Brigham, M.D., and Parker, K.K. (2011). Blast-induced phenotypic switching in cerebral vasospasm. Proc Natl Acad Sci U S A 108, 12705-12710. doi: 10.1073/pnas.1105860108.

Armstead, W.M. (1999). Endothelin-1 contributes to normocapnic hyperoxic pial artery vasoconstriction. Brain Res 842, 252-255. doi: 10.1016/S0006-8993(99)01825-9.

Arutiunov, A.I., Baron, M.A., and Majorova, N.A. (1974). The role of mechanical factors in the pathogenesis of short-term and prolonged spasm of the cerebral arteries. J Neurosurg 40, 459-472. doi: 10.3171/jns.1974.40.4.0459.

Barry, D.I., Strandgaard, S., Graham, D.I., Braendstrup, O., Svendsen, U.G., Vorstrup, S., Hemmingsen, R., and Bolwig, T.G. (1982). Cerebral blood flow in rats with renal and spontaneous hypertension: resetting of the lower limit of autoregulation. J Cereb Blood Flow Metab 2, 347-353. doi: 10.1038/jcbfm.1982.33.

Bastide, M., Bordet, R., Pu, Q., Robin, E., Puisieux, F., and Dupuis, B. (1999). Relationship between inward rectifier potassium current impairment and brain injury after cerebral ischemia/reperfusion. J Cereb Blood Flow Metab 19, 1309-1315. doi:

10.1097/00004647-199912000-00003.

Bayliss, W.M. (1902). On the local reactions of the arterial wall to changes of internal pressure. $J$ Physiol 28, 220-231. 
Bell, E.D., Kunjir, R.S., and Monson, K.L. (2013). Biaxial and failure properties of passive rat middle cerebral arteries. Journal of Biomechanics 46, 91-96. doi:

10.1016/j.jbiomech.2012.10.015.

Bell, E.D., Sullivan, J.W., and Monson, K.L. (2015). Subfailure overstretch induces persistent changes in the passive mechanical response of cerebral arteries. Frontiers in Bioengineering and Biotechnology 3. doi: 10.3389/fbioe.2015.00002.

Boock, R.J. (1991). Vascular Response to Mechanical Deformations. Ph.D., University of Pennsylvania.

Bukoski, R.D., Wang, S.N., Bian, K., and Dewitt, D.S. (1997). Traumatic brain injury does not alter cerebral artery contractility. American Journal of Physiology 272, H1406-1411.

Cantu, R.C., and Gean, A.D. (2010). Second-impact syndrome and a small subdural hematoma: an uncommon catastrophic result of repetitive head injury with a characteristic imaging appearance. J Neurotrauma 27, 1557-1564. doi: 10.1089/neu.2010.1334.

Cdc (2013). CDC grand rounds: reducing severe traumatic brain injury in the United States. MMWR Morb Mortal Wkly Rep 62, 549-552.

Coronado, V.G., Xu, L., Basavaraju, S.V., Mcguire, L.C., Wald, M.M., Faul, M.D., Guzman, B.R., and Hemphill, J.D. (2011). Surveillance for traumatic brain injury-related deaths-United States, 1997-2007. MMWR Surveill Summ 60, 1-32.

Czosnyka, M., Smielewski, P., Kirkpatrick, P., Menon, D.K., and Pickard, J.D. (1996). Monitoring of cerebral autoregulation in head-injured patients. Stroke 27, 1829-1834. Davis, M.J. (1993). Myogenic response gradient in an arteriolar network. Am J Physiol 264, H2168-2179. 
Dewitt, D.S., and Prough, D.S. (2003). Traumatic cerebral vascular injury: the effects of concussive brain injury on the cerebral vasculature. J Neurotrauma 20,795-825. doi: $10.1089 / 089771503322385755$.

Donato, A.J., Lesniewski, L.A., and Delp, M.D. (2007). Ageing and exercise training alter adrenergic vasomotor responses of rat skeletal muscle arterioles. J Physiol 579, 115-125. doi: 10.1113/jphysiol.2006.120055.

Ellison, M.D., Erb, D.E., Kontos, H.A., and Povlishock, J.T. (1989). Recovery of impaired endothelium-dependent relaxation after fluid-percussion brain injury in cats. Stroke 20, 911-917. doi: 10.1161/01.STR.20.7.911

Faraci, F.M., and Heistad, D.D. (1990). Regulation of large cerebral arteries and cerebral microvascular pressure. Circ Res 66, 8-17. doi: 10.1161/01.RES.66.1.8

Finney, D.J. (1976). Radioligand Assay. Biometrics 32, 721-740.

Golding, E.M. (2002). Sequelae following traumatic brain injury. The cerebrovascular perspective. Brain Res Brain Res Rev 38, 377-388.

Golding, E.M., Contant, C.F., Jr., Robertson, C.S., and Bryan, R.M., Jr. (1998a). Temporal effect of severe controlled cortical impact injury in the rat on the myogenic response of the middle cerebral artery. J Neurotrauma 15, 973-984.

Golding, E.M., Robertson, C.S., and Bryan, R.M., Jr. (1998b). Comparison of the myogenic response in rat cerebral arteries of different calibers. Brain Res 785, 293-298. doi: S0006899397014194 [pii].

Golding, E.M., Robertson, C.S., and Bryan, R.M., Jr. (1999a). The consequences of traumatic brain injury on cerebral blood flow and autoregulation: a review. Clin Exp Hypertens 21, 299-332. 
Golding, E.M., Steenberg, M.L., Contant, C.F., Jr., Krishnappa, I., Robertson, C.S., and Bryan, R.M., Jr. (1999b). Cerebrovascular reactivity to CO(2) and hypotension after mild cortical impact injury. Am J Physiol 277, H1457-1466.

Golding, E.M., Steenberg, M.L., Johnson, T.D., and Bryan, R.M., Jr. (2000). The effects of potassium on the rat middle cerebral artery. Brain Res 880, 159-166. doi: 10.1016/S00068993(00)02793-1.

Hamel, E. (2006). Perivascular nerves and the regulation of cerebrovascular tone. J Appl Physiol (1985) 100, 1059-1064. doi: 10.1152/japplphysiol.00954.2005.

Hardy, W.N., Mason, M.J., Foster, C.D., Shah, C.S., Kopacz, J.M., Yang, K.H., King, A.I., Bishop, J., Bey, M., Anderst, W., and Tashman, S. (2007). A study of the response of the human cadaver head to impact. Stapp Car Crash Journal 51, 17-80.

Harper, S.L., Bohlen, H.G., and Rubin, M.J. (1984). Arterial and microvascular contributions to cerebral cortical autoregulation in rats. Am J Physiol 246, H17-24.

Jamal, A., Bendeck, M., and Langille, B.L. (1992). Structural changes and recovery of function after arterial injury. Arterioscler Thromb 12, 307-317.

Jiang, X., and Kopp-Schneider, A. (2014). Summarizing EC50 estimates from multiple doseresponse experiments: a comparison of a meta-analysis strategy to a mixed-effects model approach. Biom J 56, 493-512. doi: 10.1002/bimj.201300123.

Johnson, P.C. (1986). Autoregulation of blood flow. Circ Res 59, 483-495. doi: 10.1161/01.RES.59.5.483

Johnson, T.D., Marrelli, S.P., Steenberg, M.L., Childres, W.F., and Bryan, R.M., Jr. (1998). Inward rectifier potassium channels in the rat middle cerebral artery. Am J Physiol 274, R541-547. 
Katayama, Y., Becker, D.P., Tamura, T., and Hovda, D.A. (1990). Massive increases in extracellular potassium and the indiscriminate release of glutamate following concussive brain injury. J Neurosurg 73, 889-900. doi: 10.3171/jns.1990.73.6.0889.

Kenney, K., Amyot, F., Haber, M., Pronger, A., Bogoslovsky, T., Moore, C., and Diaz-Arrastia, R. (2016). Cerebral Vascular Injury in Traumatic Brain Injury. Exp Neurol 275 Pt 3, 353366. doi: 10.1016/j.expneurol.2015.05.019.

Kontos, H.A., Raper, A.J., and Patterson, J.L. (1977). Analysis of vasoactivity of local pH, PCO2 and bicarbonate on pial vessels. Stroke 8, 358-360. doi: 10.1161/01.STR.8.3.358

Kontos, H.A., and Wei, E.P. (1992). Endothelium-dependent responses after experimental brain injury. J Neurotrauma 9, 349-354. doi: 10.1089/neu.1992.9.349.

Laskowski, R.A., Creed, J.A., and Raghupathi, R. (2015). "Pathophysiology of Mild TBI: Implications for Altered Signaling Pathways," in Brain Neurotrauma: Molecular, Neuropsychological, and Rehabilitation Aspects, ed. F.H.P. Kobeissy. (Boca Raton $(\mathrm{FL}))$.

Lassen, N.A. (1974). Control of cerebral circulation in health and disease. Circ Res 34, 749-760. doi: 10.1161/01.RES.34.6.749.

Len, T.K., and Neary, J.P. (2011). Cerebrovascular pathophysiology following mild traumatic brain injury. Clin Physiol Funct Imaging 31, 85-93. doi: 10.1111/j.1475097X.2010.00990.x.

Maas, A.I., Stocchetti, N., and Bullock, R. (2008). Moderate and severe traumatic brain injury in adults. Lancet Neurol 7, 728-741. doi: 10.1016/S1474-4422(08)70164-9.

Marrelli, S.P., Johnson, T.D., Khorovets, A., Childres, W.F., and Bryan, R.M., Jr. (1998). Altered function of inward rectifier potassium channels in cerebrovascular smooth 
muscle after ischemia/reperfusion. Stroke 29, 1469-1474. doi:

10.1161/01.STR.29.7.1469.

Martin, N.A., Doberstein, C., Zane, C., Caron, M.J., Thomas, K., and Becker, D.P. (1992).

Posttraumatic cerebral arterial spasm: transcranial Doppler ultrasound, cerebral blood flow, and angiographic findings. J Neurosurg 77, 575-583. doi:

10.3171/jns.1992.77.4.0575.

Mathew, B.P., Dewitt, D.S., Bryan, R.M., Jr., Bukoski, R.D., and Prough, D.S. (1999).

Traumatic brain injury reduces myogenic responses in pressurized rodent middle cerebral arteries. J Neurotrauma 16, 1177-1186. doi: 10.1089/neu.1999.16.1177.

Narayan, R.K., Maas, A.I., Servadei, F., Skolnick, B.E., Tillinger, M.N., Marshall, L.F., and Traumatic Intracerebral Hemorrhage Study, G. (2008). Progression of traumatic intracerebral hemorrhage: a prospective observational study. J Neurotrauma 25, 629-639. doi: 10.1089/neu.2007.0385 [doi].

Nilsson, P., Hillered, L., Olsson, Y., Sheardown, M.J., and Hansen, A.J. (1993). Regional changes in interstitial $\mathrm{K}+$ and $\mathrm{Ca} 2+$ levels following cortical compression contusion trauma in rats. J Cereb Blood Flow Metab 13, 183-192. doi: 10.1038/jcbfm.1993.22.

Osol, G., Brekke, J.F., Mcelroy-Yaggy, K., and Gokina, N.I. (2002). Myogenic tone, reactivity, and forced dilatation: a three-phase model of in vitro arterial myogenic behavior. Am J Physiol Heart Circ Physiol 283, H2260-2267. doi: 10.1152/ajpheart.00634.2002.

Prat, R., Markiv, V., Dujovny, M., and Misra, M. (1997). Evaluation of cerebral autoregulation following diffuse brain injury in rats. Neurol Res 19, 393-402. 
Robertson, C.S., Contant, C.F., Gokaslan, Z.L., Narayan, R.K., and Grossman, R.G. (1992). Cerebral blood flow, arteriovenous oxygen difference, and outcome in head injured patients. J Neurol Neurosurg Psychiatry 55, 594-603. doi: 10.1136/jnnp.55.7.594.

Seals, D.R., Jablonski, K.L., and Donato, A.J. (2011). Aging and vascular endothelial function in humans. Clin Sci (Lond) 120, 357-375. doi: 10.1042/CS20100476.

Simard, J.M., Kilbourne, M., Tsymbalyuk, O., Tosun, C., Caridi, J., Ivanova, S., Keledjian, K., Bochicchio, G., and Gerzanich, V. (2009). Key role of sulfonylurea receptor 1 in progressive secondary hemorrhage after brain contusion. J Neurotrauma 26, 2257-2267. doi: 10.1089/neu.2009.1021 [doi].

Smirnov, S.V., and Aaronson, P.I. (1992). $\mathrm{Ca}^{2+}$ currents in single myocytes from human mesenteric arteries: evidence for a physiological role of L-type channels. J Physiol 457, 455-475. doi: 10.1113/jphysiol.1992.sp019387.

Takahashi, H., Manaka, S., and Sano, K. (1981). Changes in extracellular potassium concentration in cortex and brain stem during the acute phase of experimental closed head injury. J Neurosurg 55, 708-717. doi: 10.3171/jns.1981.55.5.0708.

Talman, W.T., and Nitschke Dragon, D. (2007). Neuronal nitric oxide mediates cerebral vasodilatation during acute hypertension. Brain Res 1139, 126-132. doi: 10.1016/j.brainres.2007.01.008.

Toklu, H.Z., Muller-Delp, J., Yang, Z., Oktay, S., Sakarya, Y., Strang, K., Ghosh, P., Delp, M.D., Scarpace, P.J., Wang, K.K., and Tumer, N. (2015). The functional and structural changes in the basilar artery due to overpressure blast injury. J Cereb Blood Flow Metab. doi: $10.1038 / \mathrm{jcbfm} .2015 .151$. 
Udomphorn, Y., Armstead, W.M., and Vavilala, M.S. (2008). Cerebral blood flow and autoregulation after pediatric traumatic brain injury. Pediatr Neurol 38, 225-234. doi: 10.1016/j.pediatrneurol.2007.09.012.

Ursino, M. (1994). "Regulation of the Circulation of the Brain," in The Human Brain Circulation: Functional Changes in Disease, eds. R.D. Bevan \& J.A. Bevan. (Totowa, NJ: Humana Press), 291-318.

Zubkov, A.Y., Lewis, A.I., Raila, F.A., Zhang, J., and Parent, A.D. (2000). Risk factors for the development of post-traumatic cerebral vasospasm. Surg Neurol 53, 126-130. doi: 10.1016/S0090-3019(99)00178-0. 


\section{Tables}

\section{Table 1}

Summary of overstretch parameters (mean \pm standard deviation) and group sizes for each test group.

\begin{tabular}{lccc}
\hline Test Groups & $\mathrm{N}$ & Overstretch Level $\left(\mathrm{X}^{*} \lambda_{\mathrm{IV}}\right)$ & Strain Rate $\left(\mathrm{s}^{-1}\right)$ \\
\hline Control & 5 & $\mathrm{~N} / \mathrm{A}$ & $\mathrm{N} / \mathrm{A}$ \\
$1.2 * \lambda_{\mathrm{IV}}$ Slow & 4 & $1.18 \pm 0.02$ & $0.28 \pm 0.02$ \\
$1.2 * \lambda_{\mathrm{IV}}$ Fast & 5 & $1.20 \pm 0.02$ & $20.63 \pm 0.59$ \\
$1.3 * \lambda_{\mathrm{IV}}$ Slow & 5 & $1.32 \pm 0.02$ & $0.33 \pm 0.09$ \\
$1.3 * \lambda_{\mathrm{IV}}$ Fast & 5 & $1.31 \pm 0.02$ & $24.49 \pm 1.90$ \\
\hline
\end{tabular}




\section{Table 2}

Best fit parameters for the four parameter logistic function used to calculate EC50 values.

\begin{tabular}{|c|c|c|c|c|c|c|c|}
\hline \multirow[b]{3}{*}{ Test Groups } & \multicolumn{7}{|c|}{ Best Fit Parameters } \\
\hline & \multicolumn{3}{|c|}{ Shared Parameters } & & \multicolumn{3}{|c|}{ EC50 (mM) } \\
\hline & Min & Max & Hillslope & & Pre-OS & 0 min Post-OS & $60 \mathrm{~min}$ Post-OS \\
\hline \multirow[t]{2}{*}{ Control } & \multirow[t]{2}{*}{8.44} & \multirow[t]{2}{*}{99.97} & \multirow[t]{2}{*}{3.22} & Mean & 27.57 & 25.25 & 23.90 \\
\hline & & & & St. Dev. & 7.48 & 6.74 & 5.28 \\
\hline \multirow[t]{2}{*}{$1.2 * \lambda_{\mathrm{IV}}$ Slow } & \multirow[t]{2}{*}{0.16} & \multirow[t]{2}{*}{100.59} & \multirow[t]{2}{*}{4.48} & Mean & 27.29 & 26.60 & 25.05 \\
\hline & & & & St. Dev. & 7.27 & 7.23 & 5.76 \\
\hline \multirow[t]{2}{*}{$1.2 * \lambda_{\mathrm{IV}}$ Fast } & \multirow[t]{2}{*}{-0.27} & \multirow[t]{2}{*}{101.32} & \multirow[t]{2}{*}{2.82} & Mean & 30.69 & 28.38 & 28.16 \\
\hline & & & & St. Dev. & 9.65 & 6.45 & 5.61 \\
\hline \multirow[t]{2}{*}{$1.3 * \lambda_{\mathrm{IV}}$ Slow } & \multirow[t]{2}{*}{4.53} & \multirow[t]{2}{*}{104.47} & \multirow[t]{2}{*}{2.85} & Mean & 33.23 & 35.09 & 36.57 \\
\hline & & & & St. Dev. & 8.41 & 9.88 & 12.80 \\
\hline \multirow[t]{2}{*}{$1.3 * \lambda_{\mathrm{IV}}$ Fast } & \multirow[t]{2}{*}{-5.10} & \multirow[t]{2}{*}{107.09} & \multirow[t]{2}{*}{2.24} & Mean & 27.26 & 31.54 & 33.01 \\
\hline & & & & St. Dev. & 13.07 & 14.97 & 17.35 \\
\hline
\end{tabular}




\section{$\underline{\text { Figure Captions }}$}

Figure 1: Representative $\mathrm{K}^{+}$dose response for a rat MCA sample (A) in terms of percent contraction $(\% \mathrm{C})$, and $(\mathrm{B})$ as viewed by the camera. Characteristic biphasic response exhibits dilation to small increases of $\mathrm{K}^{+}$and contraction to high $\mathrm{K}^{+}$concentrations. Baseline $\mathrm{KCl}$ concentration is $4.7 \mathrm{mM}$. Scale bar at image right is $100 \mu \mathrm{m}$

Figure 2: $\Delta \% \mathrm{C}$ (mean \pm standard error) as a function of $\mathrm{KCl}$ concentration for (A) controls and (B-E) following various levels and rates of axial overstretch. Controls show changes in contractility with repeated exposures to identical dosing sequences. Comparison of overstretch and control groups shows that the ability of vessels to contract tends to be impaired following higher, faster overstretch. "*" indicates statistical difference from the time-matched control group measurement.

Figure 3: Percent change in EC50 for all five test groups, displayed as mean \pm standard deviation. Results show that changes in EC50 tend to increase with higher, faster overstretch. "**" indicates statistical difference from the time-matched control group measurement. 


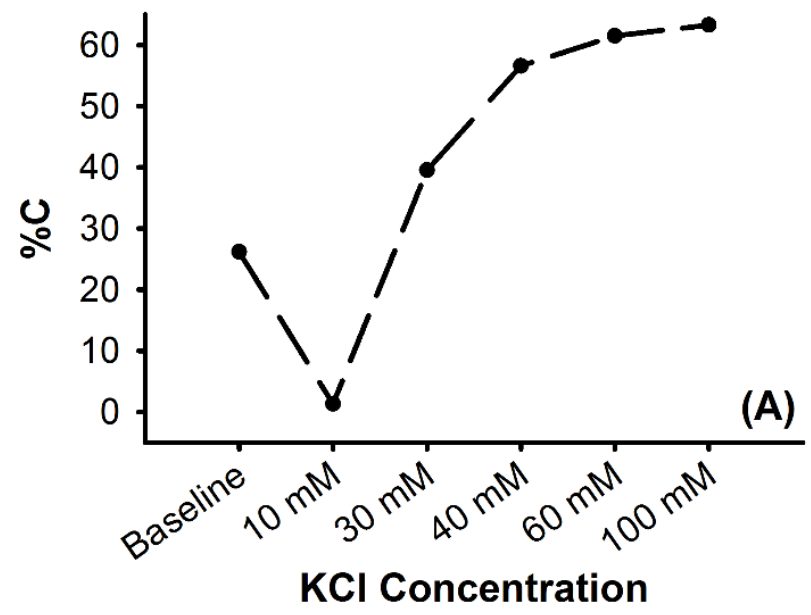




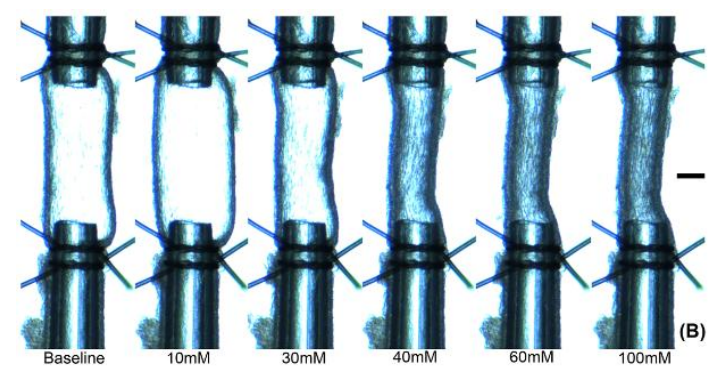



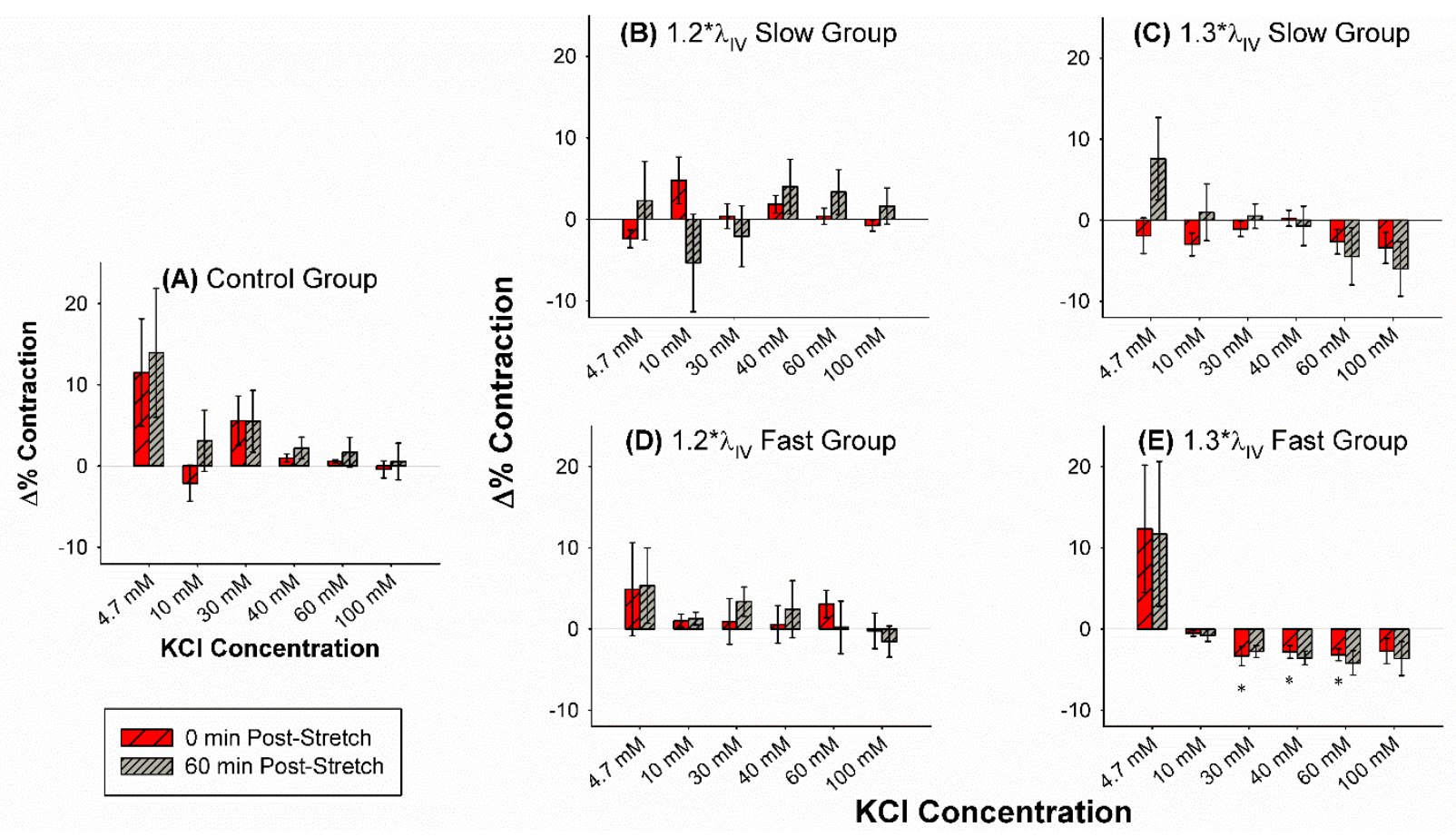


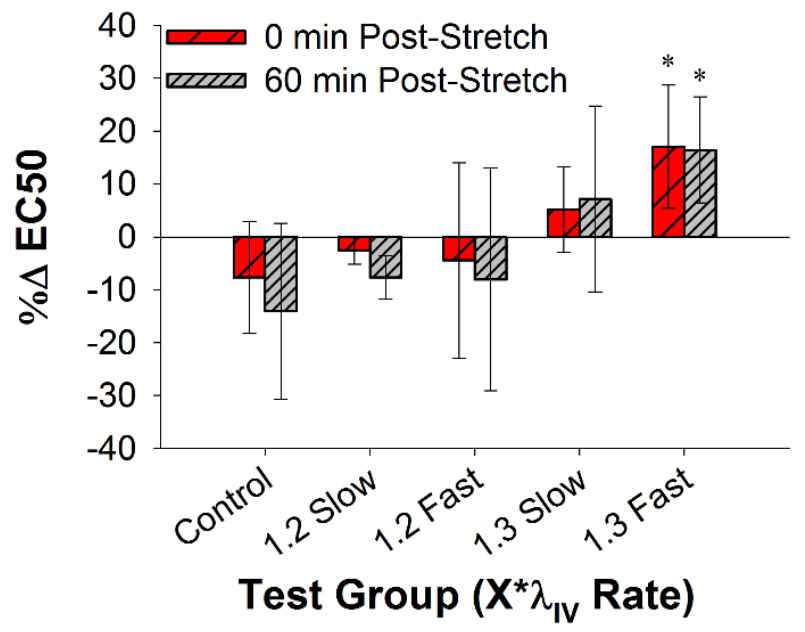

